\title{
LIBMAK: A PROGRAM TO MANIPULATE ANISN-TYPE BINARY LIBRARIES
}

BY

WILLIAM G, PRICE

\section{PLASMA PHYSICS LABORATORY}

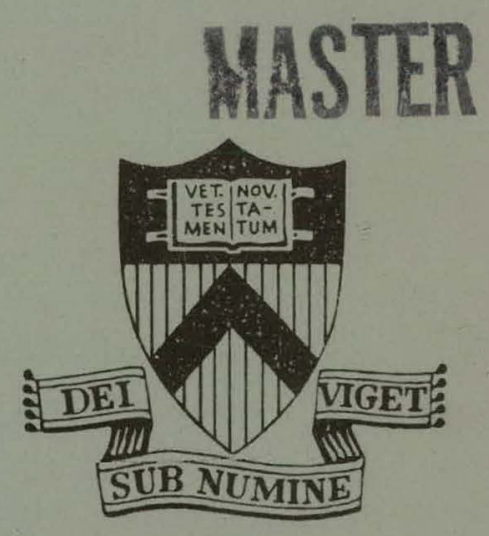

\section{PRINCETON \\ UNIVERSITY PRINCETON, NEW JERSEY}

This wnrk was supported by U.S. Atomic Energy Commlssion Contract AI $111-11$-3073. Reproduction, transla-
tion, publication, use, and disposal, in whole or in part, by or for the United States Covernment is permitted. 


\section{DISCLAIMER}

This report was prepared as an account of work sponsored by an agency of the United States Government. Neither the United States Government nor any agency Thereof, nor any of their employees, makes any warranty, express or implied, or assumes any legal liability or responsibility for the accuracy, completeness, or usefulness of any information, apparatus, product, or process disclosed, or represents that its use would not infringe privately owned rights. Reference herein to any specific commercial product, process, or service by trade name, trademark, manufacturer, or otherwise does not necessarily constitute or imply its endorsement, recommendation, or favoring by the United States Government or any agency thereof. The views and opinions of authors expressed herein do not necessarily state or reflect those of the United States Government or any agency thereof. 


\section{DISCLAIMER}

Portions of this document may be illegible in electronic image products. Images are produced from the best available original document. 


\title{
IIBMAK: A Program to Manipulate ANISN-Type Binary Libraries*
}

\author{
William G. Price, Jr. \\ Plasma Physics Iaboratory, Princeton University \\ Princeton, New Jersey 08540
}

\begin{abstract}
IIBMAK is a program written to manipulate ANISNtype binary libraries. Input data may be taken from old libraries or card decks in AREAD (FIDO) format. Commands ale avallable to create, revise, combine, list, and punch material data stored in ANISN binary form.
\end{abstract}

This report was O T C E

sponsored was prepared as an account of work the United States United States Government. Neither Commits States nor the United 3tutes Atomic Energy their contrac nor any of their employces, nor any of their contractors, subcontractors, or their nor any of

makes any warranty, express or implied employees,

legal liability or responsibility for the or assumes any

pleteness or uscfuluess of any for the accuracy, com-

product or process disclos information, apparatus,

would not infringe privately owied rignts.

\section{MASTER}

*This work was supported by U. S. Atomic Energy Commission Contract AT(11-1)-3073 and by the Electric Power Research Institute Project RP-113. Use was made of computer facilities supported in part by National Science Foundation Grant NSF-GP 579 : 


\section{INTRODUCTION}

The program LIBMAK has been; written to simplify the generation and maintenance of data libraries formated for the ANTN code. Both card libraries and binary libraries can be handled. The data need not actually be ANISN cross sections as long as it has the: appropriate structure. Input data are specified using the flexible AREAD (FIDO) formats: 


\section{ANISN-Type Libraries}

Libraries being maintained in the ANISN format consist of sets of two-dimensional matrices $x(K, L)$ together with their identifying cards or records. The first dimension, $K$, indicates the number of rows, called "positions" (IGM) in ANISN nomenclature; the second dimension, I, indicates the number of columns, or "groups" (IHM). The matrix X may contain any kind of data; LIBMAK only needs to know the proper dimensions. (Vectors can be handled also, by setting $K=1$ or $L=1$. )

There is a limit on the size of matrices which can be processed by any given version of LIBMAK; that is, the number of elements ( $K \times$ L) cannot exceed a certain limit. In the current version of LIBMAK this limit is 6000 elements, but it can be increased or decreased very easily.

There are five identifying items associated with each matrix: $\mathrm{K}$, the number of positions (rows); $\mathrm{L}$, the number of groups (columns); IC, a control parameter; ID, an identifying number; and a LABEL up to 48 characters long.

The ID number number is used to select the associated matrix. The LABEL is ignored by LIBMAK but is of obvious use in describing - the data identified by ID. The control parameter is used only to indicate the logical end of a library by setting IC $=7$; LIBMAK ignores other values.

An ANISN-type library punched on cards consist of alternating Marker Cards and Data Cards. A Marker Card contains the identifying data for the following matrix. The standard format. (4I6, I2A4) is used to punch ( $\mathrm{L}, \mathrm{K}, \mathrm{IC}, \mathrm{ID}, \mathrm{IABEL})$. The Data Cards 
contain the elements of $X(K, L$ ) in AREAD (FIDO) format.

Binary libraries also consist of alternating Marker Records and Data Records, but they are read and written with the FORTRAN "unformatted" READ and WRITE statements:

$$
\begin{aligned}
& \text { WRITE (IIB) } \\
& \text { WRITE (LIB) }
\end{aligned} \quad((X(I, I C, I D, I=I, K), J=I, L)
$$

A binary library must be terminated with a dummy End-of-pata Marker Record containing IC $=7$.

\section{Data Sets}

The input to and output from IIBMAK is distributed among six logical data sets. Each has a default unit number, indicated in the descriptions, below; unit numbers 3, 5, 8, and 9 can be reset during execution to facilitate the merging or splitting of libraries

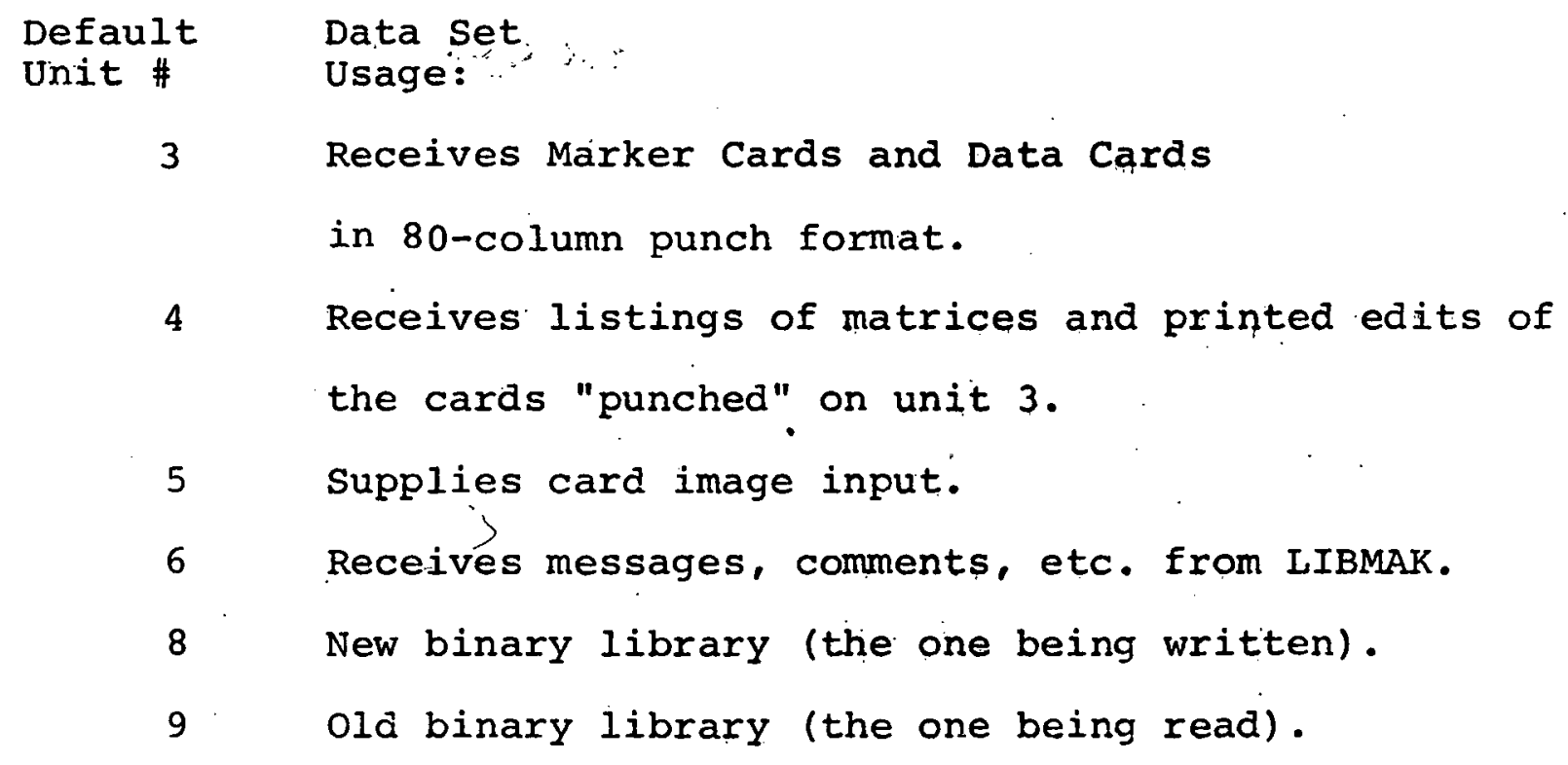

Default Unit \#

\section{Data set.}

$$
\text { Usage:" }
$$

\section{Receives Marker Cards and Data Cards}

in 80-column punch format.

Receives listings of matrices and printed edits of the cards "punched" on unit 3. Supplies card image input. Receives messages, comments, etc. from LIBMAK. New binary library (the one being written). old binary library (the one being read). 


\section{Input and output}

The primary input to LIBMAK consists of Control Cards, some . of which may require additional data. The standard format $(3,(A I, I X), E I 4.0,60 X)$ is used to read the control items $W, H, E$, and $\mathrm{V}$; comments may be punched beyond column 20. W("what") and H("how") specify the requested operation; E("edit") indicates the type of editing desired; while V("value") may supply a numerical parameter. (Note that a number punched in in the V-field must either be right-justified or contain a decimal point.)

Some of the IIBMAK operations require additional input information." Numerical data will be read by the AREAD input data procesising routine and should therefore be supplied in AREAD (FIDO) format. (Note that an "array number" is not required, although one may be used to change the scan mode). Numeric data must be terminated with a " $T$ " code to prevent AREAD from trying to process Control Cards.

Normai program termination is induced by an End-of-File on the irput unit; any matrix still active will be written onto the New Library unit. Tarmination may also be caused by the discovery of any of a number of error conditions. In either case, an Endof-File record will be written onto the New Library if any matrices have previously been added to it. 
LIBN:AK writes on the message unit (6) a running commentary on the operations being performed. This inlcudes an echo of all control cards, confirmation of library manipulations, and descriptions of any errors encountered. Selective edits (printed or punched) of the matrices being processed can be obtained by use of the "E" parameter.

The legal values of $\mathrm{E}$ for each command are indicated in the command descriptions below. Generally the choices are "L", "T", or "P". If $E=L$, the matrix is printed in ANISN format (positions as rows, groups as columns, 8 columns per page) on the Listing unit (4); if $E=T$, the transpose of the matrix is printed. If $E=P$, a Marker Card is sent to the Punch unit (3), followed by the matrix in AREAD "fixed" format, using only the,+- , and $Q$ data codes; the same records are echoed on the Listing unit. If $E=C$, only the matrix changes are listed, as indicated in the command descriptions.

Commands affecting a whole library $(W=L)$ are treated specially. If $E=L$ or $T$ or $P$, the editing is applied to every matrix in the library. If $E=I$ an index of the Marker Records is written onto the Message unit $(6)$. The anomalous $\mathrm{E}=\mathrm{A}$ is described along with the library commands. 
Commands

LIBMAK can find and read matrices from an old library (regardless of order); it can read whole matrices or matrix corrections from the Input unit; and it can write (possibly revised) matrices on a New library. Internally it maintains two storage areas: one where "Active" matrices are held while being directly manipulated; and a "Buffer", initialized to zero, in which matrices can be accumulated and saved.

The commands for IIBMAK are described below, where $W, H, E$, and $V$ are read with the format $(3(A l, 1 X), E 14.0,60 X)$.

\begin{tabular}{|c|c|c|c|}
\hline$\underline{\mathrm{H}}$ & Command & Edit Choices & $\mathrm{V}$ requirements \\
\hline C & Comment & E ignored & $V$ ignored \\
\hline
\end{tabular}

This command is ignored; columns 21 through 80 may be used for comments.

L $O$ old Library $\quad \mathrm{E}=\mathrm{L}, \mathrm{T}, \mathrm{P}, \mathrm{I}, \mathrm{A} \quad \mathrm{V}$ required

If $E \neq A$, the current old Library unit is rewound, then the old library unit number is changed to "V" and rewound. If $E=A$, the current old library is positioned just past the matrix with ID $=V$.

L N New Library $\quad E=L, T, P, I, \lambda \quad V$ roquircd

If $E \neq A$, the current Active matrix (if any) is written on the New library; then if any matrices have been written an End-of-Data record is written; and the current New library is rewound. Finally the New library unit number is changed to ."V". and rewound.

If $E=A$, the current New library is positioned just past the matrix with ID $=V$.
L P Library Punch
E ignored
$\mathrm{V}$ required

The unit number for "punched" output is changed to V. 
F $N$ Find New

$E=I, T, P$

$\mathrm{V}$ optional

The Active matrix (if any) is written on the New library, and a new Active matrix is read from the Input unit. The input is expected to consist of a Marker Card, followed by the matrix Data Cards, terminated with a "T". The data is read by $A R E A D$ with free-format if $V=0$ or with fixedformat if $\mathrm{V} \neq 0$.

$F \mathrm{~S}$ Skip and Find

$E=L, T, P$

$\mathrm{V}$ required

If the Active matrix has ID $=V$, no further action is taken. Otherwise the Active matrix (if any) is written on the New library, and a new Active matrix is read from the old library; matrices are read and discarded until one with $\mathrm{ID}=\mathrm{V}$ is found. (If necessary, one rewind will be issued to ensure that the whole library is scanned.)

F C Copy and Find

$E=L, T, P$

$\mathrm{V}$ required

This option is like the Skip-and-Find except that all matrices read from the old library until ID $=\mathrm{V}$ is found are copied directly to the New library.

$\mathrm{F} B$ Find in Buffer $\quad \mathrm{E}=\mathrm{L}, \mathrm{T}, \mathrm{P} \quad \mathrm{V}$ ignored

The Active matrix. (if any) is written on the New library, and a new Active matrix is read from the Buffer region. A Marker Card to identify the matrix is read from the Input unit. Finally the Buffer is erased.

$F \quad$ Find Nothing $\quad E=L, T, P \quad V$ ignored

The Active matrix (if any) is written on the New library without being replaced.

B A Add to Buffer $\quad \mathrm{E}=\mathrm{L}, \mathrm{T}, \mathrm{P} \quad \mathrm{V}$ required

Each element of the Buffer matrix is increased by " $V$ " times the corresponding element of the Active matrix, which is left unchanged.
B $S$ Save in Buffer
$E=L, T, P$
$\mathrm{V}$ required

This option is like the Add-to-Buffer except that the Active matrix is deleted.

B E Erase the Buffer $E$ ignored $V$ ignored

The entire Buffer is re-initialized to zero. 
B D Dump the Buffer $\quad E=L, T, P \quad V$ required

Each elenent of the Buffer matrix is multiplied by "V"; then a Marker card to identify it is read from the Input unit. Finally the matrix is written on the New library, and the Buffer is erased.

B . Buffer Nothing . $E=L, T, P \quad V$ ignored

The only action taken is to check the edit request.
A E Alter by Erasure
E ignored
V ignored

The Active matrix (if any) is erased.
A S Alter Scale
$E=L, T, P$
$\mathrm{V}$ required

The whole Active matrix is multiplied by "V" (or by 1.0 if $\mathrm{V}=0$ ).

A I Alter Trentification E ignored V ignored

A Marker card is read from the Input unit, and the ID and LABEL replace those of the current Active matrix.
A D Alter Dimensions
$E=L, T, P$
$\checkmark$ ignored

A Marker card is read from the Input unit, and the dimensions on the card are used to reformat the Active matrix. If the number of rows (positions) or columns (groups) changes, the Active matrix is contracted by truncation or expanded by padding with zeros.

A $T$ Alter by Transposing $E=L, T, P \quad V$ ignored

The whole Active matrix is transposed, and the values of the dimensions are interchanged.
A G Alter Group
$E=L, T, P, C$
$\checkmark$ required

New elements for group (column) " $V$ " of the Active matrix are read from the Input unit in AREAD free-format (terminated with $a$ "T"). If $E=C$, only the changed group is listed.

A $P$ Alter Position $\quad E=L, T, P, C \quad V$ required

New elements for position (row) " $V$ " of the Active matrix are read from the Input unit in $A R E A D$ free-format (terminated with $a$ "T"). If $E=C$, only the changed position is listed. 
A C Alter Column Order $E=I, T, P, C$

$\mathrm{V}$ ignored

The order of the columns (groups) of the Active matrix will be revised. A control vector of integers $M(I)$, one for each column, is read from the Input unit in AREAD free-format (terminated with a "T"). If any $M(I)$ is $<0$ or $>$ \# of columns, it is reset to $I$. Then column I of the altered Active matrix is filled with column $M(I)$ of the original Active matrix, or with zeros if $M(I)=0$. If $E=C$, only the control vector $M(I)$ is listed.
A. R Alter Row Order
$E=L, T, P, C$
$\mathrm{V}$ ignored

This option is similar to the Alter-Column-Order command, except that the control vector $M(I)$ is applied to the rows. (positions) rather than the columns.
A Alter Nothing
$E=L, T, P$
$\mathrm{V}$ ignored

The only action taken is to check the edit request. 


\section{Programer's Guide}

LIBMAK has been written entirely in FORTRAN-IV for the IBM/360. It has been compiled on the Princeton University $360 / 91$ in about 10 seconds with the FORTRAN-H compiler. The memory required to execute the resulting code is roughly $64 \mathrm{k}$ bytes plus 16 bytes $x$ maximum \# matrix elements plus I/O buffers.

The maximum number of matrix elements can be easily changed by altering the dimensions of the four internal arrays $\mathrm{X}, \mathrm{T}, \mathrm{B}$, and $\mathrm{Z}$, and revising the value given to the parameter MAX. Each of these five numbers should be set to the maximum allowable value of ( $\mathrm{K} \times \mathrm{L})$, the number of matrix elements. The subroutine MAKLIB contains a "version date" which is printed out when LIBMAK is executed; this should be changed whenever LIBMAK is revised.

The routine AREAD is used to process most numerical input. This code (descended from ANISN's FIDO) is fully documented. ${ }^{\dagger}$ All other subroutines referenced are included with the LIBMAK package with the exception of INDUMP. This performs no direct function and can be eliminated; at Princeton it sets up a special debugging procedure for intercepting Abnormal Terminations.

\footnotetext{
${ }^{\dagger}$. G. Price, Jr., "AREAD, An Input Processing Routine,"
} Princeton Plasma Physics Laboratory 'MATT-1034 (1974). 
LEGAL NOTICE

This report was prepared as an account of Government sponsored work. Neither the United States, nor the Commission, nor any person acting on behalf of the Commission:

A. Makes any warranty or representation, express or implied, with respect to the accuracy, completeness, or usefulness of the information contained in this report, or that the use of any information, apparatus, method, or process disclosed in this report may not infringe privately owned rights; or

B. Assumes any liabilities with respect to the use of, or for damages resulting from the use of any information, apparatus, method, or process disclosed in this report.

As used in the above, "person acting on behalf of the Commission" includes any employee or contractor of the Commission to the extent that such employee or contractor prepares, handles or distributes, or provides access to, any information pursuart to his employment or contract with the Commission. 
